\title{
Sustainable ecological and economic development of mountainous areas through the prism of tariff regulation of nature management
}

\author{
Mykhaylo Pityulych ${ }^{1, *}$, Mariana Popyk ${ }^{2}$, Galyna $\mathrm{Kish}^{2}$, Olga Chakiy ${ }^{1}$, and Robert Bacho ${ }^{3}$ \\ ${ }^{1}$ Uzhhorod National University, Department of Finance and Banking, 3 Narodna Sq, 88000 \\ Uzhhorod, Ukraine \\ ${ }^{2}$ Uzhhorod National University, Department of Tourism Infrastructure and Hotel-Restaurant Industry, \\ 3 Narodna Sq, 88000 Uzhhorod, Ukraine \\ ${ }^{3}$ Ferenc Rakoczi II Transcarpathian Hungarian College of Higher Education, Department of \\ Accounting and Audit, 6 Koshut street, 90200 Berehovo, Ukraine
}

\begin{abstract}
The article is focused on the formation of an effective tariff policy for the use of natural resources and environmental pollution. The article substantiates that such a policy should be aimed at minimizing the negative impact of economic and business activities on the environment, which will ultimately increase the efficiency and rational use of available natural resources of separate mountain areas based on their development priorities. The main factors are outlined that stipulate for the complexity and urgency of solving environmental problems in mountain areas, where special attention is focused on the impact of existing economic entities on the use of local natural resources and the impact of their activities on the environment is determined. The article defines the methodological tools for calculating the assessment of the impact of investment projects on the environmental situation of a particular area where the investment project will be implemented. The study reveals methods for calculating two indicators related to emissions of harmful substances into the environment, in particular the calculation of the coefficients of ecological purity of productions for atmosphere and water in some separate areas.
\end{abstract}

\section{Introduction}

The study of the scientific issue of sustainable ecological and economic development of the mountainous territories of the Ukrainian Carpathians is due to their extremely important role in the life of the country, the formation of global environmental security. The presence of rare natural resources, unique objects of endangered species of plants and animals, healing balneal springs make these areas an exceptional natural heritage that needs to be developed and preserved. Unlike many mountain ranges, the Carpathian Mountains are home to almost 1.3 million people in our country, which has preserved a unique diversity of

\footnotetext{
*Corresponding author: mykhaylo.pityulych@uzhnu.edu.ua
} 
ethno cultural heritage of the mountain population, traditions of management in difficult climatic conditions, attitude to work as the most important human value.

However, mountain areas today are not only an area of negative socio-economic trends, but also an example of inefficient nature management policies, which together have created a situation where mountain villages are beginning to die out massively. Therefore a strategically important task at the present stage is to conduct an effective regional policy aimed at ensuring sustainable use of nature, which requires consideration of regional features of natural resources, determining their structure and assessing the socio-economic efficiency of their development. This is especially true for the use of natural resource potential of mountain regions, which with an exceptional ecological role are characterized by relatively low economic development and relevant socio-demographic problems and require special approaches to sustainable regional development policy, including nature management, where special attention should be paid to effective tariff environmental policy, which will limit the natural impact of people on the environment and reduce the anthropogenic impact on it.

The above mentioned indicates the relevance of the chosen research topic and justifies its feasibility in modern conditions.

\section{Degree of scientific development}

Regional studies of sustainable ecological and economic development of mountain areas have been reflected in the works of many domestic and foreign scientists. In particular, V. Miklovda, M. Pitiulych, V. Hoblyk, M.Pityulych and N. Keretsman [1] have conducted research and analysis of key parameters of life of the population of small mountain settlements in the Transcarpathian region. M. Kichkovsky devoted many of his works [2] to the research of economic, ecological and social problems of sustainable development of the Carpathians and other mountain regions.

In the works of I. Dragan [3] there is paid great attention to the problems of implementation of state policy of nature management in mountainous areas. In this context, the research of M. Prikhodko [4, 9] also deserves attention, as he has focused much attention on the regional geological research and environmental management in the mountain areas. It is impossible to avoid a significant contribution to the development of the mountain areas of V. Kravtsiv [5], who devoted a significant part of his work to the study of socio-economic, natural-ecological and ethnocultural features of the development of mountainous areas of Ukraine. O.Adamenko, Ya. Adamenko and V. Bulmasov [6] have revealed the natural principles of the environmental monitoring of the Carpathian region in their scientific works.

Much attention of scientists, including such as A.Biswas, Qu.Geming [7], Sheresheva M. [8] has been devoted to the study of anthropogenic impact on the environment and the delineation and evaluation of possible methods of its assessment. Special attention needs to be paid to such scientists as B. Burkynskyi, H. Shevchenko, M. Petrushenko, N. Khumarova [11], I. Mikhno, V. Koval, G. Shvets, O. Garmatiuk and R. Tamošiūnienė [10], who have focused on the study of the green economy and elucidation of its impact on sustainable development of regions and increasing the resource efficiency. Such scientists as L. Cherchyk, M. Shershun, N. Khumarova, T. Mykytyn and A. Cherchyk [12] have paid attention to the study of the functioning of various enterprises in mountainous areas, including forestry, as well as to clarify their impact on the sustainable environmental and economic development of these areas. 


\section{Results and discussion}

The urgency of environmental problems in mountainous areas and the complexity of their solution at the present stage are obvious, as most mountainous areas have become areas with high levels of environmental pollution, or with devastating human impact on natural resources, which requires urgent measures to save nature and restore normal human life, which is the key to sustainable environmental and economic development not only of these areas but also the region as a whole. At the same time, trying to improve the current situation, it is very important to ensure the stability of economic and social development of these areas and prevent a global environmental disaster in the future.

The key to this issue is the environmental and economic approach to the development and evaluation of investment programs and individual projects, as well as the evaluation of the activities of existing economic entities in these areas.

Nowadays there are number of factors that make especially difficult to solve environmental problems in our conditions, in particular:

1. The environmental emergency that has developed in some areas and in the country as a whole and as a result of economic growth policy, which provides a purely economic rather than humanistic orientation of investment and activities of existing enterprises.

2. The inertia of the process of deterioration of the environmental situation is due to the fact that along with the existing facilities, new projects are being developed and implemented, which already have the same principles as before. We are talking about the use of old technologies, morally and physically obsolete equipment, making inefficient technical and organizational decisions on the use of existing environmental and technical potential.

3. The deficit of budgets at all levels (state, regional, local), as well as the lack of sufficient financial resources of individual enterprises [1], provoked the situation related to the existence of trend "residual principle" in relation to social and environmental problems.

4. Structural changes in investment activities, namely a decrease in the share, and in some areas the lack of public investment in socio-economic development, growth of the business sector, the emergence of so-called non-local investors [2]. In the conditions of unregulated legal norms of economic relations, insufficient level of competence, and often intentional ignoring of the ecological aspect in decision-making can lead to significant negative changes in the already existing unfavorable situation. One of the mechanisms to prevent incompetent decisions is the independent examination of programs and projects that will be implemented here, as well as the assessment of existing enterprises in terms of balanced use of natural resources and minimizing their negative impact on the environment.

When a facility operates in a particular area, it initially, as a rule, significantly changes the conditions prevailing in this region (and even beyond it) in the field of social and industrial infrastructure, natural and labour resources, in terms of environmental welfare.

Therefore, for the effective functioning of economic entities and entrepreneurship it is necessary to conduct a comprehensive assessment of the natural resource potential of the territory, as well as to analyze the impact on existing resources due to the operation of existing or construction of new facilities.

The natural resource potential should be understood as all types, species and groups of sources of livelihood of people in a particular region - natural, technical, economic, cultural, historical, social infrastructure, as well as a human - the main and most valuable resource, with whom ensures the use of all other resources in the region. One of the most important tasks in solving this problem is to develop a methodology for economic, cost evaluation of all types of resources, as only on the basis of analytical data can enter a reasonable fee for resource use, for damage caused by pollution and resource degradation 
[3]. Only in this case it is possible to create economic examination of projects or operating productions.

Control over existing enterprises and assessment of the quality of potential investment projects is a very important moment in the management of enterprises and clarifying their impact on the development of local economic systems. The adopted new advanced solutions can ensure structural changes in economics. Therefore, the task - to assess the quality of use of natural resources - should be carried out for all enterprises, economic entities and for any investment project - whether state or regional, or any existing or created by a separate production and economic unit - by union, enterprise [4].

Particular attention should be paid to assessing the use of natural resource potential of investment projects, because for the existing enterprises there are established; and regulations are applied according to which they have already operated and therefore transfer them to new rails with new approaches to the use of these resources are postponed in time. And the lack of proper scientific analysis at the formation stages of investment programs often leads to unreasonable and irrational strategic decisions, deliberately misdirecting project developers, resulting in inefficient production, or has a negative impact on the environmental situation in mountain villages.

Transferring the assessment to the level of the finished technical project makes it impossible to make fundamental changes in construction. Firstly, it is because a lot of money has been spent and time has been lost, because it only takes 3-4 years to develop the programs themselves, not to mention their approval, taking into account our bureaucratic approaches to such issues, and their implementation. Secondly, taking into account the commissioning of the given production, new production and economic ties have already been planned for some time. Thirdly, due to the lack of alternative design practice, it is impossible to replace this project with another, more efficient one [5].

The same problem of assessment arises at the stage of construction and development of the object. The adopted changes in design decisions can be both expedient and biased, to a large extent reflect someone's subjective interests. They may be due, for example, to the following circumstances: the inability or unwillingness of managers to perform them; the need to improve the project; the results of forecasting the consequences of these decisions, taking into account the directions of development of scientific and technological progress, etc.

A study of foreign experience shows that in world practice the assessment of pre-project developments is given the most attention. It is at this point that it is still permissible to make a reasonable decision that satisfies the economic interests and does not conflict with the interests and capabilities of the region. If at this stage an objective assessment is given taking into account the already formed conditions and forecasts of the region and industry, the tasks of the designers are largely defined. Next is the choice of technical and construction solutions, project examination, evaluation of the implementation of target installations in the most economical way.

In the developed countries at the pre-project stages are widely used environmental and economic models of various types: optimization, simulation, combined. The difficulties arising in their implementation are associated with the monetary evaluation of indicators and their comparison, as well as often with the disagreement of some entrepreneurs with the strengthening of the environmental aspect of the analysis [6].

In developing countries, the so-called methods of rapid assessment (express analysis) the method of "ad hoc", checklists, matrices, the method of overlay, the grid method $[7,8]$ became widespread. A prerequisite for their application is alternative management of economic and business activities and also future investment projects.

These methods are based on the assessment of the impact of future projects and current activities on the environment, and on living conditions in the region. 
Analyzing the specific difficulties that arise in the implementation of a holistic environmental and economic approach to the assessment of entrepreneurial activity in our country, we highlight the following: the lack of the necessary information base, primarily for environmental assessment; lack of experience in organizing and conducting expert evaluations at the interdisciplinary level; organization of ecological and economic expertise to manage the minimum costs arising from the general state of finances; psychological unpreparedness of administrations in the center and on the ground for such an approach.

These specified points make the situation in our country similar to that in the developing countries. It follows that it is the most acceptable in our conditions to develop and implement various options for express assessments [9].

Exactly this position is the basis of our proposed methodology for assessing the quality of use of natural resources at enterprises in mountainous areas.

The proposed methodology provides a qualitative analysis of possible adverse effects of economic entities in the process of their activities, as well as due to the implementation of new investment projects on the economic, social and environmental situation in mountainous areas.

Unfortunately, the current regulatory documentation offers very "poor" ecological characteristics for the functioning of economic entities. These indicators are as follows: the volume of emissions of harmful substances into the atmosphere and water; the number of captured and neutralized substances, etc. As for the negative impact on forest resources and subsoil, the situation is generally critical, because, as noted earlier, official statistics and real data differ significantly, especially in such indicators as deforestation area, reforestation area and so on.

With regard to tariff and price policy for the use of forest resources, it should be noted that the imperfect distribution of forest management and forestry functions affects the effectiveness of the formation and implementation of pricing policy in forestry in Ukraine. Thus, the Concept of Forestry Reform and Development formulates the goals of the pricing policy, but they need to be supplemented and detailed. The principal organ in the formation of pricing policy in forestry is the State Agency of Forest Resources of Ukraine, which through formal and informal levers of influence influences the formation of supply of forest products, the cost of forestry products, setting limits on forest resources. However, the process of formation and implementation of pricing policy should be transparent, with the involvement of stakeholders. It is expedient to harmonize the interests of stakeholders with the help of forest programs, which are widely implemented in the practice of creating forest policy in highly developed foreign countries. The pricing policy in the forestry of Ukraine should be focused on the maximum extension of the value chain of forest products and the fullest possible use of the full range of forest resources of the state, especially in a moratorium on the export of raw timber abroad. The point is that one of the instruments of tariff policy in forestry, which will stimulate the integrated use of forest resources, is the holding of investment forums and the sale of investment projects to create production facilities for processing forest resources. The State Agency of Forest Resources of Ukraine, along with investment projects, can implement long-term contracts for the sale of forest resources that are not in demand. This tool will allow creating additional jobs not only in mountainous areas, but also in those areas where there is a low level of industrial development, which will increase the efficiency of forest resources [10, 11, 12]. In addition, this tool can be fully implemented at the level of the State Agency of Forest Resources of Ukraine without additional agreement with the government or the Verkhovna Rada of Ukraine.

With regard to other natural resources, in order to increase the informativeness of environmental characteristics, we propose to introduce two new indicators relating to pure emissions of harmful substances, while abstracting from the assessment of the negative 
impact on forest resources and subsoil, - coefficients of ecological purity of productions which are operating or are planning to operate in these areas, for the atmosphere $\left(\mathrm{Catm}_{\text {epp }}\right)$ and water $\left(C w_{\text {epp }}\right)$ :

$$
C_{a t m} \text { epp }=\frac{\bar{U}^{a t m}}{U^{a t m}}, C w_{e p p}=\frac{\bar{U}^{w}}{U^{w}},
$$

where $U^{a t m}, U^{w}$ - total emissions of harmful substances into the atmosphere and water, respectively (t/year); $\bar{U}^{a t m}, \bar{U}^{w}$ - volumes of captured, neutralized and utilized harmful substances $(\mathrm{t} /$ year).

Obviously, that this assessment is quite general, as both existing enterprises and potential investment projects that meet the accepted standards for emissions of harmful substances can vary greatly in the degree of their negative impact on the environment. It is determined, as a rule, by the qualitative composition of emissions and the current environmental situation in the region.

In the course of further research we received an assessment of the degree and possible directions of harmful effects of harmful substances emissions on the atmosphere and air. For this, all substances emitted into the atmosphere and water were sorted by the degree of their toxicity and the magnitude of the deviation of emissions from the maximum allowable emissions. In addition, the analysis required the introduction of coefficients of the ecological situation and the ecological state of atmospheric air and water objects in mountainous areas and river basins, as well as standards of payment for emissions of pollutants into the air and water bodies.

To solve this problem, we have identified three stages. At the first stage, a given number of toxicity classes of all pollutants emitted into the atmosphere and water were formed, for the emissions of which, according to regulations, a fee is charged. After that, for the list of harmful emitted substances at existing enterprises, as a rule, or assessed as such, which will be carried out in the project documentation, groups are built on the basis of toxicity and the magnitude of deviations from the emission limit. At the third stage, an assessment of the total economic loss from the emission of all pollutants that are or will be carried out by enterprises in the course of their activities.

For a mathematical description of such a problem, we introduce the following initial notations: $E_{i}^{a t m}$ - a pollutant that is emitted into the atmosphere; $E_{i}^{w}$ - a pollutant that is emitted into the water bodies; $S_{i}^{\text {atm }}$ - a standard of payment for emissions into the air $1 \mathrm{t}$ $E_{i}^{a t m}$ within the norms of permissible emissions; $S_{i}^{w}-$ a standard of payment for emissions into water bodies $1 \mathrm{t} E_{i}^{w}$ within the norms of permissible emissions; $\widetilde{S}_{i}^{a t m}-$ a standard of payment for emissions into the atmosphere $1 \mathrm{t} E_{i}^{\text {atm }}$ above the allowable emissions; $\widetilde{S}_{i}^{w}-$ a standard of payment for emissions into water bodies $1 \mathrm{t} E_{i}^{w}$ above the allowable emissions; $m$ - number of toxicity classes; $r$-number of emission groups.

We will carry out the formation of toxicity classes of pollutants.

We assume that a given number of toxicity classes is equal to $m$.

We build a grouping for standards of payment for emissions of pollutants into the atmosphere within the allowable emissions $S_{i}^{\text {atm }}$ and into water bodies $S_{i}^{w}$. For this, we divide the range of value changes $S_{i}^{a t m}$ into $m$ equal intervals $\Delta_{j}(j=1,2, \ldots, m)$.

We denote by $h$ the value of the interval: 


$$
h=\frac{S_{\max }^{a t m}-S_{\min }^{a t m}}{m},
$$

where $S_{\max }^{\text {atm }}$ and $S_{\min }^{\text {atm }}$ - maximum and minimum of the variable value $S_{i}^{\text {atm }}$ respectively.

Then $\Delta_{i}=\left[S_{\text {min }}^{\text {atm }}+(j-1) h ; S_{\text {min }}^{a t m}+j h\right]$.

We can say if for $S_{s}^{a t m}$ is standard of payment for the emission of the substance $(s)$ $S_{s}^{a t m} \in \Delta_{j}(s=1,2, \ldots, q)$, then the degree of harmfulness (rank of harmful effects) of substance pollutant is equal to $j$.

Thus, all air polluted substances are divided into $m$ toxicity classes $T_{1}, \ldots, T_{m}$, the numbers of which increase with decreasing degree of harmful effects. Hence, if $S_{s}^{a t m} \in \Delta_{j}$, than $E_{s}^{a t m} \in T_{j}$.

Each class of pollutants $T_{j}(j=1,2, \ldots, m)$ is characterized by: a) the number of pollutants belonging to this class; $b$ ) the average for the class value of the standards of payment $\bar{S}_{T_{j}}^{\text {atm }} ;$ c) the minimum value of the standard of payment for this class $\bar{S}_{\min T_{j}}^{a t m}$ d) the maximum value of the standard of payment for this class $\bar{S}_{\max T_{j}}^{a t m}$.

Similarly, the grouping of standards of payment for emissions of pollutants into water bodies and the formation of toxicity classes for water pollutants is carried out.

Degree assessment of harmful effects of pollutants is carried out as follows.

Let suppose that according to some project or activity of an existing enterprise into atmosphere is emitted $D^{a t m}$ pollutants, and into water bodies $-D^{w}$.

If the emission value of some substance $E_{s}^{a t m}$ is equal to $U_{s}^{a t m}$ and $E_{s}^{a t m} \in T_{j}$, then the ecological impact of this substance can be characterized: firstly, by the number of the toxicity class $j$, to which $E_{s}^{\text {atm }}$ refers; the level (\%) of the deviation of the emission value $U_{s}^{a t m}$ from the norm of the maximum emission of the substance; we denote it by $X$.

$$
X=\frac{U_{s}^{a t m}-\widetilde{U}_{s}^{a t m}}{\widetilde{U}_{s}^{a t m}} \cdot 100,
$$

where $\widetilde{U}_{s}^{a t m}$ - the value of the maximum allowable emissions for the substance emitted into the atmosphere.

To characterize the degree of harmful effects of the whole set of $D^{a t m}$ pollutants emitted into the air, we build a grouping of these substances on the basis of toxicity and the level of deviation of emission values from the maximum allowable emissions.

Each of the pollutants from the number $D^{a t m}$ belongs to one of the toxicity classes $T_{j}$. We denote $D_{j}^{a t m}$ - the amount of substance from the number $D^{a t m}$, which belongs to $\mathrm{j}$ toxicity class. Then the distribution of the whole set of pollutants according to the degree of harmful effects can be written as follows:

$$
D_{1}^{a t m} \in T_{1}, D_{2}^{a t m} \in T_{2}, \ldots, D_{m}^{a t m} \in T_{m}
$$




$$
\sum_{j=1}^{m} D_{j}^{a t m}=D^{a t m}
$$

Next, we determine the proportion of substances of each toxicity class in the total number of air pollutants $D^{a t m}$. For this we find

$$
\max _{j} \frac{D_{j}^{a t m}}{D^{a t m}} \cdot 100=\frac{D_{S_{1}}^{a t m}}{D^{a t m}} \cdot 100
$$

and then we arrange the proportion $\frac{D_{j}^{a t m}}{D^{a t m}} \cdot 100(j=1,2, \ldots, m)$ in descending order, entering the following denotation:

$$
\frac{D_{S_{1}}^{a t m}}{D^{a t m}} \cdot 100=\widetilde{D}_{1}, \frac{D_{S_{i}}^{a t m}}{D^{a t m}} \cdot 100=\widetilde{D}_{i}(i=1,2, \ldots, m),
$$

where $S_{i}$ - the number of toxicity class of substances, for which proportion $\frac{D_{S_{1}}^{a t m}}{D^{a t m}} \cdot 100$ takes $i$ place in the series of ordered values $\frac{D_{j}^{a t m}}{D^{a t m}} \cdot 100$, we obtain a vector

$$
K=\left(\widetilde{D}_{1}, \widetilde{D}_{2}, \ldots, \widetilde{D}_{i}, \widetilde{D}_{i+1}, \ldots, \widetilde{D}_{m}\right)
$$

for which $\widetilde{D}_{i+1} \leq \widetilde{D}_{i}(i=1,2, \ldots, m-1)$.

It gives a clear idea of the structure of emissions of the whole set of $D^{\text {atm }}$ pollutants and the degree of their harmful effects on the atmosphere.

The obtained assessment of the harmful effects of pollutants can be supplemented by grouping them according to the level of deviation of emissions from the maximum allowable emissions.

To do this, we set $r$ the values of the level of deviation of emissions from the maximum allowable emissions $X_{1}, X_{2}, \ldots, X_{r},\left(X_{1}<X_{2}<\ldots<X_{r}\right)$, according to which we form $r$ groups of emissions $Q_{1}, Q_{2}, \ldots, Q_{r}$. Each of the pollutants $E_{s}^{a t m}$ can be attributed to one of these groups $Q_{j}(j=1,2, \ldots, r)$. Denote by $D_{X}^{a t m}$ the number of substances included in the group $Q_{j}, \sum_{j=1}^{r} D_{X_{j}}^{a t m}=D^{a t m}$. Then the vector $K_{X}=\left(D_{X_{1}}, \ldots, D_{X_{r}}\right)$ presents the distribution of pollutants by emission groups.

In addition, for each of the groups $Q_{j}$, an estimate of the maximum and mean toxicity of the substances included in it can be found.

Similar considerations and constructions are carried out for all $D^{w}$ water-polluting substances listed in the project or which are already being implemented in practice.

To determine the quantity of the economic damage from the emission of pollutants, additional notations were introduced: $P_{s}^{a t m}$ - amount of payment for the emission of pollutants into the atmosphere $E_{s}^{a t m} ; P_{s}^{w}$ - amount of payment for the emission of 
pollutants into water bodies $E_{s}^{w} ; C E S^{a t m}$ - coefficient of ecological situation and ecological significance of atmospheric air condition; $C E S^{w}$ - coefficient of ecological situation and ecological significance of water bodies condition.

Then if $U_{s}^{a t m} \leq \widetilde{U}_{s}^{a t m}$, then $P_{s}^{a t m}=U_{s}^{a t m} \cdot S_{s}^{a t m} \cdot C E S^{a t m}$; if $U_{s}^{a t m}>\widetilde{U}_{s}^{a t m}$, then $P_{s}^{a t m}=\left[\widetilde{U}_{s}^{a t m} \cdot S_{s}^{a t m}+\left(U_{s}^{a t m}-\widetilde{U}_{s}^{a t m}\right) \cdot S D_{s}^{a t m}\right] \cdot C E S^{a t m}$.

Similarly, the amount of payment for the emission of pollutants into water bodies is determined: $P_{s}^{w}=U_{s}^{w} \cdot S_{s}^{w} \cdot C E S^{w}$, if $U_{s}^{w} \leq \widetilde{U}_{s}^{w} ; P_{s}^{w}=\left[\widetilde{U}_{s}^{w} \cdot S_{s}^{w}+\left(U_{s}^{w}-\widetilde{U}_{s}^{w}\right) \cdot S D_{s}^{w}\right] \cdot C E S^{w}$, if $U_{s}^{w}>\widetilde{U}_{s}^{w}$.

The total amount of environmental damage is calculated as a sum $P_{s}^{a t m}+P_{s}^{w}$, where $P_{s}^{a t m}=\sum_{s} P_{s}^{a t m}, P_{s}^{w}=\sum_{s} P_{s}^{w}$

\section{Conclusions}

The proposed method is essentially new. The use of the proposed approach to assess the qualitative characteristics of environmental impact and economic damage from emissions of economic entities in mountainous areas provides increased validity of decisions greatly simplifies the analysis and perception of its results by experts and reduces the negative impact on the environment in mountainous areas, which will ultimately affect the livelihoods of the inhabitants of these areas.

The above mentioned allows us to conclude that to ensure the sustainable development of mountainous regions, special attention should be paid to the implementation of effective state policy of environmental protection, which is based on the development of an effective tariff and price policy for natural resources, which will minimize the negative the impact of economic and business activities on the environment and to achieve the rational use of available natural resources of certain areas.

\section{References}

1. Miklovda, V., Pitiulych, M., Hoblyk, V., Pityulych, M. (Jn.), \& Keretsman, N. (2020). Socio-Economic Transformations of Small Rural Settlements of Zakarpattia Amidst Decentralisation. International Journal of Criminology and Sociology, 9, 3089-3094. https://doi.org/10.6000/1929-4409.2020.09.375.

2. Kichkovsky, M. (2010). Sustainable development of the Carpathians and other mountain regions is the key to preserving the ecological and climatic balance of the whole of Europe. International scientific-practical Conference "Sustainable Development of the Carpathians and other mountainous regions of Europe", 11-20.

3. Dragan, I. (2011). Directions for the implementation of state policy in the field of nature management in Ukraine. Bulletin of the Academy of Customs Service of Ukraine. Series: Public Administration, 1, 37-42.

4. Prikhodko, M. (2006). Regional geoecological research and rational use of nature (on the example of Ivano-Frankivsk region). Ivano-Frankivsk: Manuscript, 245.

5. Kravtsiv, V. (2012). Ukrainian Carpathians: state policy and strategic priorities of sustainable development. Socio-economic problems of the modern period of Ukraine, 93, 11-19. 
6. Adamenko, O., Adamenko, Ya., \& Bulmasov V. (1996). Natural bases of ecological monitoring of the Carpathian region. Kyiv: Manuscript, 208.

7. Biswas, A., \& Geming, Qu. (1987). Environmental impact assessment for developing countries. London: Manuscript, 260.

8. Sheresheva, M. (1992). Evaluation of projects taking into account the environmental factor: the possibility of using foreign experience. Moscow University Bulletin, Series "Economics", 2, 55-64.

9. Prikhodko, M., \& Prikhodko, M. (Jn.). (2004). Management of natural resources and environmental activities. Ivano-Frankivsk: Manuscript, 820.

10. Mikhno, I., Koval, V., Shvets, G., Garmatiuk, O., \& Tamošiūnienè, R. (2021). Green Economy in Sustainable Development and Improvement of Resource Efficiency. Central European Business Review, 10(1), 99-113. https://doi.org/10.18267/j.cebr.252.

11. Shevchenko, H., Petrushenko, M., Burkynskyi, B., \& Khumarova, N. (2021). SDGs and the ability to manage change within the European green deal: The case of Ukraine. Problems and Perspectives in Management, 19(1), 53-67. https://doi.org/10.21511/ppm.19(1).2021.05.

12. Cherchyk, L., Shershun, M., Khumarova, N., Mykytyn, T., \& Cherchyk, A. (2019). Assessment of forest enterprises' performance: integrating economic security and ecological impact. Entrepreneurship and Sustainability Issues, 6(4), 1784-1797. https://doi.org/10.9770/jesi.2019.6.4(17). 